with emphasis being placed on developing outlets for basic research, which continues to be strong in Britain. Thus Professor Peckham is keen that there should, for example, be means to develop vaccines to exploit new technologies like magnetic resonance imaging.

The strategy will be implemented through the management executive and the regions, each of which will be required to produce a research and development plan. The research will have to be multidisciplinary with input from NHS professional staff, managers, and scientists, and because the NHS lacks many of the skills necessary universities will play a central part. All regional plans will need to include proposals for training. Professor Peckham foresees two tensions: firstly, between getting everybody involved and spreading the effort too thin; and, secondly, between the top down and bottom up approaches. All research organisations struggle with these tensions, but Professor Peckham believes that the NHS can achieve a balance. Thus many of the proposals for research will come from regions, but at the same time some half a dozen national priorities will be set. There will be a national research and development committee, and it may be that the committee will need a subcommittee to award grants.

In order to implement the strategy Professor Peckham and his team have been busy forming links with the Medical Research Council, the medical research charities, industry, and international organisations. Thus he imagines that the United Kingdom Coordinating Committee for Cancer Research might provide a model for other categories of research, and one is already being talked of for cardiovascular research. Working groups have also been set up to look at priorities, technology assessment, clinical evaluation, and screening, and there are other groups concerned with implementation and data handling.

What Professor Peckham and his team have produced is not a fully formed strategy, it is a bold sketch; and now begins the difficult part of trying to make it work. As every business school graduate knows, thinking up strategies is the easy part.
It's making them work that is hard, and there are some worries about this one. Firstly, it's not clear how the research strategy will relate to the overall health strategy that the Department of Health is about to produce. The World Health Organisation argues that all countries should have a research strategy - but it should underpin the overall health strategy..$^{2-4}$

A second problem with the British strategy is how the MRC will fit in. It has long been closer to scientists than the health service and may well feel threatened by this potential rise of a research empire larger than itself within the NHS. Past relations between the Department of Health and the MRC have not been happy, and the money intended for health services research has already been taken away from the MRC and given back again at least once. One radical solution might be for the MRC to receive its funds not from the Department of Education and Science but from the Department of Health. This model, which works well in Australia, ${ }^{5}$ might make the council more sensitive to NHS needs and improve the transfer of research ideas into practice.

A final problem with the grand strategy could be people. Does Britain have enough health service and public health researchers, epidemiologists, health economists, and the like to make the plan work? Many people doubt that it does, but Professor Peckham thinks that there may be more such researchers around than people realise. Let's hope that he is right, because an organisation as large as the NHS undoubtedly needs a coherent research strategy and people to make it happen.

RICHARD SMITH Editor, $B M \mathcal{F}$

\footnotetext{
1 House of Lord Select Committee on Science and Technology. Priorities in medical research. London: HMSO, 1988.

World Health Organisation Regional Office for Europe. Research policy for health for all. Copenhagen: WHO, 1988.

World Health Organisation Regional Office for Europe. Priority research for health for all. Copenhagen: WHO, 1988

Smith R. A national health research policy. BM7 1988;297:805-6.

5 Smith R. Life on the broad side: medical research. BMf 1991;302:897-900.
}

\title{
Heart transplantation in children
}

\section{Short term results are encouraging}

The technical feasibility of heart transplantation in infancy was established in $1967,{ }^{1}$ but uncertainties regarding its long term prognosis and the adverse consequences of immunosuppression, accompanied by complex ethical questions, delayed progress. The improved prognosis of heart transplantation in adults after the introduction of cyclosporin encouraged some centres to embark on paediatric transplantation in the early 1980s.

Indications for transplantation in childhood are end stage cardiomyopathy and congenital heart disease when conventional surgery is not feasible, carries prohibitive risks, or provides poor palliation. ${ }^{2}$ The short term to intermediate term prospects for children undergoing transplantation are reasonably favourable. Currently, actuarial survival of $80 \%$ at one year and $62 \%$ at five years is being achieved. ${ }^{3+}$ Excellent quality of life is reported, ${ }^{3-6}$ although the psychological sequelae of transplantation in children have not been studied in detail. From the limited data available it seems that graft function remains normal, at least up to six years after transplantation, with normal growth of myocardium and arterial anastomoses ${ }^{7}$ and normal exercise capacity in these children. ${ }^{89}$

By the end of 1989, 169 transplant operations had been performed worldwide in infants (children less than 1 year old), of whom two thirds were less than 2 months old. ${ }^{+}$It is in infants and neonates (less than 1 month old) that the merits of transplantation have been most vigorously debated, and recent correspondence aired profound concerns over the ethics and expense of what is generally regarded as an experimental procedure. ${ }^{10-1+}$ Only Bailey's group at Loma Linda has much experience of neonatal transplantation; they recently reported that 21 of 25 infants survived four to 40 months after transplantation for the hypoplastic left heart syndrome, which is otherwise invariably fatal within a few weeks of birth. ${ }^{15}$ Interestingly, Bailey et al have suggested that the ideal time for transplantation may be in the preterm or neonatal period, as "immunologic privilege" ensures that the host response is less aggressive and more easily controlled. ${ }^{16} 17$ This window of opportunity appears to last for only the first 30 days of life. ${ }^{16}{ }^{17} \mathrm{~A}$ further problem in neonatal transplantation is the source of donor organs. In July 1988, after a public outcry, the Loma Linda group stopped using anencephalic donors as only three of 14 such babies fulfilled the criteria for brain death and only one proved suitable for transplantation. ${ }^{18}$ 
Serious concerns remain over the long term prognosis for children who receive transplants. Accelerated coronary atherosclerosis, believed to represent chronic, humorally mediated rejection, ${ }^{19}$ occurs in up to half of adult patients within five years of transplantation. ${ }^{20}$ Children are probably equally susceptible to accelerated atherosclerosis, ${ }^{51}$ although neonates may be more resistant because of their immature immune state. ${ }^{16}$ Cyclosporin, the cornerstone of immunosuppressive treatment, invariably produces hypertension and renal damage, which may itself eventually necessitate transplantation. To avoid the many troublesome side effects of steroids and in particular their adverse effects on growth, development, and physical appearance in children, ${ }^{22}$ some groups have advocated using cyclosporin and azathioprine for maintenance immunosuppression. ${ }^{36}$ Malignancy, most commonly lymphoproliferative disease, occurs in at least $4 \%$ of paediatric patients who have received transplants but is reversible in half by stopping immunosuppressive treatment and treating with acyclovir."

Predicting the eventual demand for paediatric transplantation is difficult. In the past five years 148 children have received a heart transplant in the United Kingdom, 44 in 1990 alone (Mr C Scott, United Kingdom Transplant Service, personal communication). Internationally, paediatric transplantation accounts for about one in 10 transplant operations but is the fastest growing group. ${ }^{+}$As the results of transplantation continue to improve, and even surpass those of some conventional procedures providing poor palliation, ${ }^{6}$ the demand is likely to grow. The increasing use of prenatal diagnosis may, however, reduce the number of infants born with severe heart defects.

At present neonatal and infant transplantation should be confined to a few centres with programmes of research and development. Parents need warning of the complexities of treatment, the exhaustive medical follow up, the uncertainties of the long term prognosis, and the considerable personal expense in time, effort, and money. Nevertheless, the prospect of offering normal early life and development to a group of patients whose condition is otherwise fatal suggests that developments in this specialty should be cautiously encouraged.

DAVID P TAGGAR'T

Senior Registrar in Cardiothoracic Surgery,

Royal Brompton National Heart and Lung Hospital,

London SW3 6HP

Senior Lecturer

JOHN H DARK

Regional Cardiothoracic Centre,

Freeman Hospital,

Newcastle upon Tyne NE7 7DN

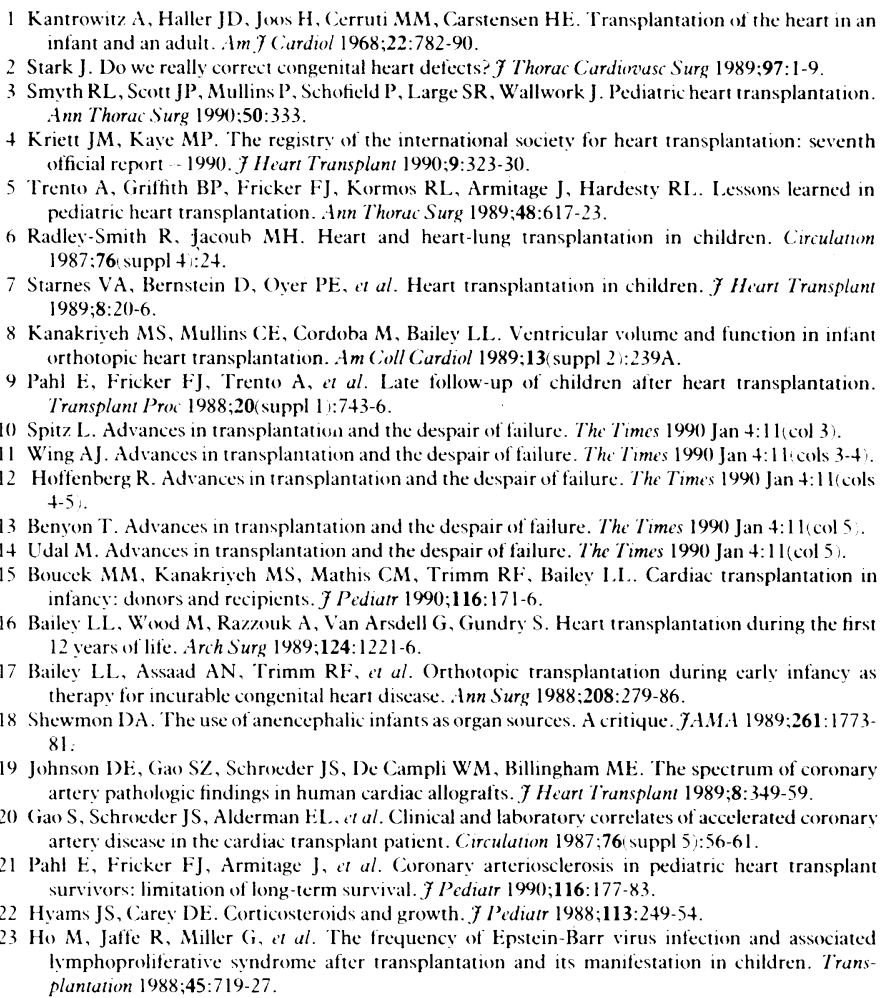

\section{Ultraviolet A radiation: staying within the pale}

\section{Sunscreens offering high sun protection factors are not enough}

The quest for a healthy suntan is largely a twentieth century phenomenon. The more we learn of ultraviolet radiation, however, the more elusive becomes that goal. Whether from sun or sunbed, ultraviolet radiation (wavelength 100-400 $\mathrm{nm}$ ) may burn as well as tan. It also causes potentially lethal skin cancers ${ }^{1}$ and the blotchy brown wrinkling of skin that accompanies aging. ${ }^{2}$ In addition, cutaneous and systemic immunological changes follow even small doses of radiation. ${ }^{3}$

Ultraviolet B radiation (wavelength $280-315 \mathrm{~nm}$ ) has been incriminated as the main waveband in terrestrial sunlight responsible for these effects. Avoiding the midday sun, particularly in summer and in the tropics, and regularly applying a sunscreen with a high sun protection factor provide reasonable protection. Sunscreens may be bought without prescription: the sun protection factor number indicates how much longer the user may stay in the sun before burning than if no sunscreen was used. These products, which contain chemicals that block ultraviolet B radiation, reduce sunburn and, at least in animals, skin aging ${ }^{+}$and cancer. ${ }^{5}$ They may, however, be less effective in preventing immunological disturbances. ${ }^{6}$ Nevertheless, the menace of acute and chronic skin damage induced by ultraviolet radiation seemed for a time to have been suitably blunted.

Now, however, a new threat has emerged from the assiduous avoidance of ultraviolet $B$ radiation: ultraviolet $A$ radiation (wavelength $315-400 \mathrm{~nm}$ ), particularly notable for its ability to tan before burning. ${ }^{?}$ Although its cutaneous effects are about 1000 times less potent than those of ultraviolet $\mathrm{B}$ rays, it is up to 100 times more intense in midday summer sunlight - thus contributing about one tenth of the total effect of ultraviolet radiation at that time. At other times, when the intensity of total ultraviolet, and particularly of ultraviolet $\mathrm{B}$, radiation falls off rapidly, it contributes a greater proportion (albeit less intense).

Without protection against ultraviolet exposure the effects of burning, mainly mediated by ultraviolet B, eventually send the sunbather inside, chastened and presumably the wiser for next time. But with careful use of highly protective sunscreens that block most of the burning ultraviolet $B$ rays the sunbather may spend much longer in the sun, during which time the much sought after tan can be achieved from the largely unfiltered ultraviolet A. Thus day after day and 